\title{
PENGARUH BERBAGAI TAKARAN PUPUK KANDANG DOMBA TERHADAP PERTUMBUHAN TANAMAN PEGAGAN (Centela asiatica L)
}

\author{
MEASURING THE EFFECT OF DIFFERENT FERTILIZER PLANT \\ GROWTH ON SHEEP COOP gotu kola (Centela asiatica L)
}

\author{
Lia Sugiarti \\ Fakultas Pertanian, Universitas Winaya Mukti \\ lia.sugiarti@gmail.com
}

\begin{abstract}
The purpose of this study was to determine the effect of various doses of sheep manure on crop growth gotu kola (Centela asiatica L). This experiment was conducted in October 2014 - February 2015 at the Experimental Faculty of Agriculture, University Winaya Mukti Andisol to soil type. The experimental design used is a randomized block design simple pattern, consisting of six sheep manure treatment dose was repeated four times. The treatment dose of sheep manure consists of: $A=$ without fertilizer; $B=5 \mathrm{th} \mathrm{a}^{-1}$; $C=$ 10 ton ha ${ }^{-1} ; D=15$ ton ha $a^{-1} ; E=20$ ton ha ${ }^{-1} ; F=25 t_{h a^{-1}}$. Results show 1) Provision of sheep manure pegagan effect on plant growth. 2) The dose of sheep manure 20-25 ton ha1 affects the kindest to the number of leaves, number of tillers, and the number of tendrils primer at 8 MST and 12 weeks after planting, and root dry weight and dry weight pupus plant gotu kola at $12 \mathrm{MST}$.
\end{abstract}

Keywords: sheep manure, crop pegagan

\section{Pendahuluan}

Seiring dengan perkembangan zaman, saat ini pemakaian obat kimia mulai dipertimbangkan mengingat efek samping jangka panjang yang akan terjadi pada kesehatan manusia. Untuk itu mulai digalakan penggunaan obatobatan alami atau herbal dari berbagai macam tanaman yang ada di sekitar kita.

Nilai perdagangan obat herbal, suplemen makanan, dan sebagainya pada tahun 2000 mencapai US\$ 40 miliar. Pada tahun 2002 meningkat menjadi US\$ 60 miliar, dan tahun 2050 diperkirakan menjadi US\$ 5 triliun dengan peningkatan $15 \%$ per tahun, lebih tinggi jika dibandingkan dengan peningkatan nilai perdagangan obat

konvensional modern yang hanya 3\% per tahun (Deptan, 2007).

Adapun tanaman obat yang digunakan diperoleh dari tanaman liar atau gulma. Salah satunya yaitu tanaman pegagan. Menurut penelitian tanaman pegagan memiliki kandungan zat kimia yang bermanfaat bagi manusia. Pegagan telah dikenal sebagai obat untuk revitalisasi tubuh dan pembuluh darah serta mampu memperkuat struktur jaringan tubuh. Pegagan dapat dikonsumsi sebagai brain tonic atau obat antilupa bagi orang dewasa dan manula, tergolong the most powerful healing herbs atau tanaman obat yang paling mujarab (Winarto dan Surbakti, 2003). 
Untuk meningkatkan pasokan obat berbahan alami tersebut, diperlukan pasokan bahan baku yang konsisten dengan mutu yang sesuai kebutuhan industi melalui usaha budidaya yang terstruktur. Untuk mendukung upaya tersebut penyedia bahan tanaman unggul merupakan salahsatu cara untuk menghasilkan bahan baku bermutu (Ghulamahdi, 2008).

Produksi pegagan untuk bahan baku obat masih terbilang jarang dan sangat terbatas, sementara permintaan sangat tinggi. Kebutuhan simplisia pegagan untuk industri jamu sebesar 126 ton per tahun, dan berada pada urutan ke 13 dari 152 simplisia (Januwati). Sehingga kendala yang utama adalah pasokan bahan baku yang terstandar dari mulai benih, pembudidayaan sampai pengolahan pasca panennya. Kebutuhan industri selama ini pegagan diambil langsung dari alam tanpa pembudidayaan sehingga pasokan bahan baku dan mutunya tidak terjamin.

Simplisia dari tanaman pegagan tersebut yaitu terpenoid khususnya tritepenoid merupakan kandungan utama pegagan, terdiri atas asiatikosida, thankunisida, isothankunisida, madekassosida, brahmosida, asam brakmat, asam madasiatat, mesoinosetol, sentelosa, karotenoid, garam $\mathrm{K}$, $\mathrm{Na}, \mathrm{Ca}, \mathrm{Fe}$, Vellarine, tanin, mucilago, resin, pektin, gula, protein, fosfor, dan vitamin B. Disamping itu, pegagan mengandung sedikit vitamin $\mathrm{C}$ dan sedikit minyak atsiri (Winarto dan Surbakti, 2003).
Untuk meningkatkan produksi asiatikosida yang merupakan hasil dari proses metabolisme sekunder pada tanaman pegagan dibutuhkan nutrisi yang cukup seperti unsur hara makro $\mathrm{N}$, $\mathrm{P}$, dan $\mathrm{K}$. Unsur hara yang diserap tanaman akan menentukan kualitas produk pertanian baik buah maupun simplisia, yang meliputi kualitas luar dan kualitas dalam. Kualitas luar meliputi penampilan, ukuran, warna dan keutuhan. Sedangkan kualitas dalam antara lain kandungan protein, vitamin, lemak, karbohidrat, metabolit sekunder dan aroma (Wijaya 2008).

Masukan nutrisi tersebut dapat berupa pemberian pupuk alami karena industri obat menginginkan penggunaan bahan alami sebagai pupuk (Tripatmasari, 2010). Pupuk kandang domba sebagai pupuk organik akan memberikan pengaruh dalam meningkatkan kualitas tanah sebagai media tanam meliputi perbaikan sifat fisika, kimia dan biologi tanah, karena pupuk kandang domba mempunyai unsur hara yang tinggi dan perbandingan ratio $\mathrm{C} / \mathrm{N}$ ratio yang rendah, sehingga akan terlapuk dengan cepat.

Penelitian ini bertujuan untuk mengetahui pengaruh berbagai takaran pupuk kandang domba terhadap pertumbuhan tanaman pegagan. Hasil penelitian ini diharapkan dapat dipergunakan sebagai salah satu sumber informasi dalam mengembangkan ilmu pertanian khususnya dalam pemanfaatan pupuk kandang domba untuk meningkatkan pertumbuhan pegagan. 


\section{Bahan dan Metode}

Percobaan dilaksanakan di

Kebun Percobaan Fakultas Pertanian Universitas Winaya Mukti, dengan ketinggian tempat $800 \mathrm{~m}$ di atas permukaan laut dan tanahnya termasuk ordo Andisol. Percobaan dilaksanakan pada bulan Oktober 2014 - Februari 2015.

Bahan yang digunakan meliputi benih pegagan, tanah, pupuk kandang domba. Alat-alat yang digunakan adalah bambu, polybag ukuran $30 \mathrm{~cm} \mathrm{x}$ $15 \mathrm{~cm}$, cutter, cangkul, embrat, tali rapia, baki plastik, plastik, kertas, alat tulis, karung, paranet, plastik, alat ukur seperti mistar, termometer, timbangan analitik, dan timbangan kapasitas $10 \mathrm{Kg}$.

Rancangan percobaan yang digunakan yaitu Rancangan Acak Kelompok (RAK) pola sederhana, yang terdiri atas enam perlakuan takaran pupuk kandang domba diulang sebanyak empat kali. Perlakuan takaran pupuk kandang domba terdiri dari : $\mathrm{A}=$ tanpa pemupukan; $\mathrm{B}=5$ ton $\mathrm{ha}^{-1} ; \mathrm{C}=10$ ton ha ${ }^{1} ; \mathrm{D}=15$ ton $\mathrm{ha}^{-1} ; \mathrm{E}=20$ ton $\mathrm{ha}^{-1} ; \mathrm{F}=25$ ton $\mathrm{ha}^{-1}$. Setiap perlakuan terdiri atas 6 polybag, sehingga jumlah menjadi 144 polybag.

Pengamatan dilakukan terhadap beberapa parameter, pertumbuhan seperti jumlah daun tanaman, jumlah anakan, jumlah sulur primer, bobot kering tanaman dan Nisbah Pupus Akar (NPA) setiap empat minggu sekali. Pengukuran dilakukan terhadap tanaman contoh yang diambil sebanyak 5 tanaman secara acak.
Percobaan ini menggunakan media tanam tanah andisol yang berasal dari Kebun percobaan Fakultas Pertanian Universitas Winaya Mukti. Tanah yang diambil untuk media tanam adalah tanah lapisan atas (top soil). Tanah dan pupuk kandang domba disaring terlebih dahulu agar didapat tanah dan pupuk kandang yang halus dan gembur. Kedua media tersebut kemudian dicampur sesuai dengan perlakuan dan dimasukan ke dalam polibag, kemudian polibag yang telah diisi disusun di atas bedengan.

Bahan tanaman yang diambil adalah anakan kedua dari ujung yang diambil dari benih pegagan yang terlebih dahulu di tanam selama 3 bulan. Sehingga diperoleh bahan tanaman yang seragam Setiap polybag diisi satu buah anakan, dengan jumlah daun tidak lebih dari tiga helai. Pemeliharaan tanaman meliputi penyiangan, penyiraman dan pengendalian hama dan penyakit tanaman. Penyiangan dilakukan pada saat tanaman, yaitu umur 4 MST dan 8 MST. Penyiraman dilakukan setiap hari atau disesuaikan dengan keadaan cuaca.

\section{Hasil dan Pembahasan}

\section{Hasil Pengamatan}

\section{1) Jumlah Daun}

Data hasil analisis pengaruh takaran pupuk kandang domba terhadap jumlah daun per tanaman pada umur 4 MST, 8 MST dan 12 MST dapat dilihat pada Tabel 1. 
Pada Tabel 1 dapat dilihat bahwa berbagai taraf takaran pupuk kandang domba menunjukkan pengaruh yang berbeda tidak nyata terhadap jumlah daun pada umur 4 MST. Pada umur 8 MST taraf takaran pupuk kandang $\mathrm{k}_{4}(20$ ton $\left.\mathrm{ha}^{-1}\right)$ dan $\mathrm{k}_{5} \quad\left(25\right.$ ton $\left.\mathrm{ha}^{-1}\right)$ menunjukkan perbedaan yang nyata dengan taraf $\mathrm{k}_{\mathrm{o}}$ (tanpa pemupukan ) dan $\mathrm{k}_{1}\left(5\right.$ ton ha $\left.{ }^{-1}\right)$, tetapi berbeda tidak nyata dengan taraf $\mathrm{k}_{2}\left(10\right.$ ton ha $\left.{ }^{-1}\right)$ dan $\mathrm{k}_{3}(15$ ton $\mathrm{ha}^{-1}$ ). Pada umur 12 MST taraf takaran pupuk kandang $\mathrm{k}_{4}\left(20\right.$ ton $\left.\mathrm{ha}^{-1}\right)$ dan $\mathrm{k}_{5}\left(25\right.$ ton $\left.\mathrm{ha}^{-1}\right)$ memberikan jumlah daun lebih baik dan berbeda nyata dibandingkan dengan $\mathrm{k}_{\mathrm{o}} \quad$ (tanpa pemupukan $), \mathrm{k}_{1}\left(5\right.$ ton $\left.\mathrm{ha}^{-1}\right)$, dan $\mathrm{k}_{2}(10$ ton $\left.\mathrm{ha}^{-1}\right)$ tetapi berbeda tidak nyata dengan $\mathrm{k}_{3}\left(15\right.$ ton $\left.\mathrm{ha}^{-1}\right)$.

\section{2) Jumlah Anakan Tanaman}

Tabel 2, menunjukkan efek mandiri dari takaran pupuk kandang domba terhadap jumlah anakan tanaman pada umur 4 MST, 8 MST dan 12 MST. Pada umur 4 MST takaran pupuk kandang domba menunjukkan pengaruh yang berbeda tidak nyata terhadap jumlah anakan tanaman tetapi memberikan jumlah anakan yang berbeda nyata pada umur 8 MST dan 12 MST.

Tabel 1. Pengaruh Takaran Pupuk Kandang Domba Terhadap Jumlah Daun Pada Umur 4 MST, 8 MST dan 12 MST.

\begin{tabular}{lccl}
\hline & \multicolumn{3}{c}{ Rata-rata Jumlah Daun } \\
\cline { 2 - 4 } Taraf Perlakuan & 4 MST & $8 \mathrm{MST}$ & $12 \mathrm{MST}$ \\
\hline Takaran pupuk kandang : & & & \\
$\mathrm{k}_{\mathrm{o}}($ tanpa pemupukan $)$ & $8,30 \mathrm{a}$ & $23,65 \mathrm{a}$ & $24,30 \mathrm{a}$ \\
$\mathrm{k}_{1}\left(5\right.$ ton $\left.\mathrm{ha}^{-1}\right)$ & $8,40 \mathrm{a}$ & $24,40 \mathrm{a}$ & $26,10 \mathrm{ab}$ \\
$\mathrm{k}_{2}\left(10\right.$ ton ha $\left.^{-1}\right)$ & $9,00 \mathrm{a}$ & $27,50 \mathrm{ab}$ & $29,25 \mathrm{~b}$ \\
$\mathrm{k}_{3}\left(15\right.$ ton $\left.^{-1}\right)$ & $9,35 \mathrm{a}$ & $28,80 \mathrm{ab}$ & $28,05 \mathrm{bc}$ \\
$\mathrm{k}_{4}\left(20\right.$ ton $\left.^{-1} \mathrm{~h}^{-1}\right)$ & $9,60 \mathrm{a}$ & $32,40 \mathrm{~b}$ & $32,60 \mathrm{c}$ \\
$\mathrm{k}_{5}\left(25\right.$ ton $\left.\mathrm{ha}^{-1}\right)$ & $9,10 \mathrm{a}$ & $30,65 \mathrm{~b}$ & $32,20 \mathrm{c}$ \\
\hline
\end{tabular}

Keterangan : Angka rata-rata yang diikuti huruf yang sama pada tiap kolom berbeda tidak nyata menurut Uji Jarak Berganda Duncan pada taraf $5 \%$.

Tabel 2. Pengaruh Takaran Pupuk Kandang Domba Terhadap Jumlah Anakan Pada Umur 4 MST, 8 MST dan 12 MST.

\begin{tabular}{|c|c|c|c|}
\hline \multirow[b]{2}{*}{ Taraf Perlakuan } & \multicolumn{3}{|c|}{ Rata-rata Jumlah Anakan } \\
\hline & $4 \mathrm{MST}$ & $8 \mathrm{MST}$ & $12 \mathrm{MST}$ \\
\hline Takaran pupuk kandang & & & \\
\hline $\mathrm{k}_{\mathrm{o}}(\operatorname{tanpa}$ pemupukan $)$ & $1,53 \mathrm{a}$ & 7,95 a & 9,95 a \\
\hline $\mathrm{k}_{1}\left(5\right.$ ton $\left.\mathrm{ha}^{-1}\right)$ & $1,64 \mathrm{a}$ & 9,40 bc & $11,85 \mathrm{~b}$ \\
\hline $\mathrm{k}_{2}\left(10\right.$ ton $\left.\mathrm{ha}^{-1}\right)$ & $1,60 \mathrm{a}$ & $10,90 \mathrm{c}$ & $13,80 \mathrm{c}$ \\
\hline $\mathrm{k}_{3}\left(15\right.$ ton $\left.\mathrm{ha}^{-1}\right)$ & $1,53 \mathrm{a}$ & $8,65 \mathrm{ab}$ & $14,30 \mathrm{~cd}$ \\
\hline $\mathrm{k}_{4}\left(20\right.$ ton $\left.\mathrm{ha}^{-1}\right)$ & $1,76 \mathrm{a}$ & $11,65 \mathrm{~d}$ & $15,65 \mathrm{~d}$ \\
\hline $\mathrm{k}_{5}\left(25\right.$ ton $\left.\mathrm{ha}^{-1}\right)$ & $1,68 \mathrm{a}$ & $11,35 \mathrm{~cd}$ & $15,05 \mathrm{~cd}$ \\
\hline
\end{tabular}

Keterangan : Angka rata-rata yang diikuti huruf yang sama pada tiap kolom berbeda tidak nyata menurut Uji Jarak Berganda Duncan pada taraf $5 \%$. 
Pada umur 8 MST taraf takaran pupuk kandang $\mathrm{k}_{4} \quad\left(20\right.$ ton $\left.\mathrm{ha}^{-1}\right)$ memberikan pengaruh yang lebih baik dan berbeda nyata dengan $\mathrm{k}_{\mathrm{o}}$ (tanpa pemupukan $), \mathrm{k}_{1}\left(5\right.$ ton $\left.\mathrm{ha}^{-1}\right), \mathrm{k}_{2}$ (10 ton $\left.\mathrm{ha}^{-1}\right)$ dan $\mathrm{k}_{3}\left(15\right.$ ton $\left.\mathrm{ha}^{-1}\right)$ tetapi berbeda tidak nyata dengan $\mathrm{k}_{5}\left(25\right.$ ton $\left.\mathrm{ha}^{-1}\right)$. Pada umur 12 MST taraf takaran pupuk kandang $\mathrm{k}_{4}\left(20\right.$ ton $\left.\mathrm{ha}^{-1}\right)$ memberikan pengaruh yang lebih baik dan berbeda nyata dengan $\mathrm{k}_{\mathrm{o}}$ (tanpa pemupukan ), $\mathrm{k}_{1}$ $\left(5\right.$ ton $\left.\mathrm{ha}^{-1}\right)$ dan $\mathrm{k}_{2}\left(10\right.$ ton ha $\left.{ }^{-1}\right)$ tetapi berbeda tidak nyata dengan $\mathrm{k}_{3}$ (15 ton $\left.\mathrm{ha}^{-1}\right)$ dan $\mathrm{k}_{5}\left(25\right.$ ton $\left.\mathrm{ha}^{-1}\right)$.

\section{3) Jumlah Sulur Primer}

Pada Tabel 4 dapat dilihat bahwa pada umur 4 MST, 8 MST dan 12 MST berbagai taraf perlakuan takaran pupuk kandang domba menunjukkan pengaruh yang berbeda tidak nyata terhadap jumlah sulur primer pada 4 MST. Pada umur 8 MST taraf takaran pupuk kandang $\mathrm{k}_{5}\left(25\right.$ ton $\left.\mathrm{ha}^{-1}\right)$ menunjukan pengaruh yang lebih baik dan berbeda nyata dengan taraf $\mathrm{k}_{\mathrm{o}}$ (tanpa pemupukan ), $\mathrm{k}_{1}\left(5\right.$ ton ha $\left.{ }^{-1}\right), \mathrm{k}_{2}\left(10\right.$ ton ha $\left.{ }^{-1}\right)$ dan $\mathrm{k}_{3}$ $\left(15\right.$ ton $\left.\mathrm{ha}^{-1}\right)$, tetapi berbeda tidak nyata dengan taraf $\mathrm{k}_{4}$ (20 ton ha $\left.{ }^{-1}\right)$. Pada umur 12 MST taraf takaran pupuk kandang $\mathrm{k}_{5}$ (25 ton ha $^{-1}$ ) menunjukkan pengaruh yang lebih baik dan berbeda nyata dengan taraf $\mathrm{k}_{\mathrm{o}}$ (tanpa pemupukan ) dan $\mathrm{k}_{1}\left(5\right.$ ton $\left.\mathrm{ha}^{-1}\right)$, tetapi berbeda tidak nyata dengan taraf $\mathrm{k}_{2}\left(10\right.$ ton $\left.\mathrm{ha}^{-1}\right), \mathrm{k}_{3}$ (15 ton $\left.\mathrm{ha}^{-1}\right)$ dan $\mathrm{k}_{4}\left(20\right.$ ton $\left.\mathrm{ha}^{-1}\right)$.

Tabel 4. Pengaruh Berbagai Takaran Pupuk Kandang Domba Jumlah Sulur Primer Pada Umur 4 MST, 8 MST dan 12 MST.

\begin{tabular}{llll}
\hline & \multicolumn{3}{l}{ Rata-rata Jumlah Sulur Primer } \\
\cline { 2 - 4 } Taraf Perlakuan & 4 MST & $8 \mathrm{MST}$ & $12 \mathrm{MST}$ \\
\hline Takaran pupuk kandang : & & & \\
$\mathrm{k}_{\mathrm{o}}($ tanpa pemupukan $)$ & $1,25 \mathrm{a}$ & $1,73 \mathrm{a}$ & $2,95 \mathrm{a}$ \\
$\mathrm{k}_{1}\left(5\right.$ ton $\left.\mathrm{ha}^{-1}\right)$ & $1,30 \mathrm{a}$ & $1,83 \mathrm{a}$ & $3,00 \mathrm{ab}$ \\
$\mathrm{k}_{2}\left(10\right.$ ton ha $\left.\mathrm{ha}^{-1}\right)$ & $1,35 \mathrm{a}$ & $1,94 \mathrm{ab}$ & $3,75 \mathrm{bc}$ \\
$\mathrm{k}_{3}\left(15\right.$ ton $\left.\mathrm{ha}^{-1}\right)$ & $1,45 \mathrm{a}$ & $1,90 \mathrm{~b}$ & $3,45 \mathrm{bc}$ \\
$\mathrm{k}_{4}\left(20\right.$ ton $\left.\mathrm{ha}^{-1}\right)$ & $1,45 \mathrm{a}$ & $2,01 \mathrm{bc}$ & $4,15 \mathrm{bc}$ \\
$\mathrm{k}_{5}\left(25\right.$ ton $\left.\mathrm{ha}^{-1}\right)$ & $1,45 \mathrm{a}$ & $1,97 \mathrm{c}$ & $3,90 \mathrm{c}$ \\
\hline
\end{tabular}

Keterangan : Angka rata-rata yang diikuti huruf yang sama pada tiap kolom berbeda tidak nyata menurut Uji Jarak Berganda Duncan pada taraf $5 \%$.

Tabel 5. Pengaruh Berbagai Takaran Pupuk Kandang Domba Terhadap Bobot Kering Tanaman, Bobot Kering Pupus, dan Bobot Kering Akar Pada Umur 12 MST.

\begin{tabular}{cccc}
\hline & $\begin{array}{l}\text { Rata-rata Bobot } \\
\text { Kering Tanaman } \\
\text { Takaran pupuk kandang : }\end{array}$ & $\begin{array}{l}\text { Rata-rata Bobot } \\
\text { Kering Pupus } \\
(\mathrm{g})\end{array}$ & $\begin{array}{l}\text { Rata-rata Bobot } \\
\text { Kering Akar }(\mathrm{g})\end{array}$ \\
\hline $\mathrm{k}_{\mathrm{o}}(\operatorname{tanpa}$ pemupukan $)$ & $0,98 \mathrm{a}$ & $8,53 \mathrm{a}$ & $9,51 \mathrm{a}$ \\
$\mathrm{k}_{1}(5$ ton ha & $-1)$ & $8,19 \mathrm{a}$ & $9,33 \mathrm{a}$ \\
$\mathrm{k}_{2}\left(10\right.$ ton ha $\left.^{-1}\right)$ & $1,13 \mathrm{a}$ & $11,20 \mathrm{~b}$ & $12,30 \mathrm{~b}$ \\
$\mathrm{k}_{3}\left(15\right.$ ton $\left.^{-1}\right)$ & $1,10 \mathrm{a}$ & $10,37 \mathrm{~b}$ & $11,40 \mathrm{~b}$ \\
$\mathrm{k}_{4}(20$ ton ha & $1,03 \mathrm{a}$ & $11,27 \mathrm{~b}$ & $12,54 \mathrm{~b}$ \\
$\mathrm{k}_{5}\left(25\right.$ ton $\left.\mathrm{ha}^{-1}\right)$ & $1,28 \mathrm{a}$ & $11,30 \mathrm{~b}$ & $12,78 \mathrm{~b}$ \\
\hline
\end{tabular}

Keterangan : Angka rata-rata yang diikuti huruf yang sama pada tiap kolom berbeda tidak nyata menurut Uji Jarak Berganda Duncan pada taraf $5 \%$. 
Tabel 6. Pengaruh Takaran Pupuk Kandang Domba Terhadap Nisbah Pupus Akar (NPA) Pada Umur 12 MST.

\begin{tabular}{|c|c|}
\hline Perlakuan & NPA \\
\hline \multicolumn{2}{|l|}{ Takaran pupuk kandang : } \\
\hline $\mathrm{k}_{\mathrm{o}}(\tan a$ pemupukan $)$ & $10,23 \mathrm{a}$ \\
\hline $\mathrm{k}_{1}\left(5\right.$ ton $\left.\mathrm{ha}^{-1}\right)$ & 8,18 a \\
\hline $\mathrm{k}_{2}\left(10\right.$ ton $\left.\mathrm{ha}^{-1}\right)$ & $11,34 \mathrm{a}$ \\
\hline $\mathrm{k}_{3}\left(15\right.$ ton $\left.\mathrm{ha}^{-1}\right)$ & $10,90 \mathrm{a}$ \\
\hline $\mathrm{k}_{4}\left(20\right.$ ton $\left.\mathrm{ha}^{-1}\right)$ & $10,14 \mathrm{a}$ \\
\hline $\mathrm{k}_{5}\left(25\right.$ ton $\left.\mathrm{ha}^{-1}\right)$ & 8,99 a \\
\hline
\end{tabular}

Keterangan : Angka rata-rata yang diikuti huruf yang sama pada tiap kolom berbeda tidak nyata menurut Uji Jarak Berganda Duncan pada taraf $5 \%$.

\section{Bobot Kering Tanaman, Bobot} Kering Pupus dan Bobot Kering Akar

Pada Tabel 5 dapat dilihat bahwa berbagai taraf takaran pupuk kandang domba menunjukkan pengaruh yang berbeda tidak nyata terhadap bobot kering tanaman pada umur 12 MST. Taraf perlakuan takaran pupuk kandang domba $\mathrm{k}_{5}\left(25\right.$ ton ha $\left.{ }^{-1}\right), \mathrm{k}_{4}\left(20\right.$ ton ha $\left.{ }^{-1}\right)$, $\mathrm{k}_{2}\left(10\right.$ ton ha $\left.{ }^{-1}\right)$, dan $\mathrm{k}_{3}\left(15\right.$ ton ha $\left.{ }^{-1}\right)$ menunjukkan pengaruh yang paling baik dan berbeda nyata dengan taraf $k_{o}$ (tanpa pemupukan ) dan $\mathrm{k}_{1}$ (5 ton ha ${ }^{-1}$ ) terhadap bobot kering pupus pada 12 MST.

Taraf takaran pupuk kandang menunjukkan pengaruh yang berbeda nyata terhadap bobot kering akar pada umur 12 MST. Taraf takaran pupuk kandang $\mathrm{k}_{5}\left(25\right.$ ton ha $\left.{ }^{-1}\right), \mathrm{k}_{4}\left(20\right.$ ton ha $\left.\mathrm{h}^{-1}\right)$, $\mathrm{k}_{2}\left(10\right.$ ton ha $\left.{ }^{-1}\right)$, dan $\mathrm{k}_{3}\left(15\right.$ ton ha $\left.{ }^{-1}\right)$ menunjukkan pengaruh yang paling baik dan berbeda nyata dengan taraf $k_{o}$ (tanpa pemupukan ) dan $\mathrm{k}_{1}\left(5\right.$ ton ha $\left.{ }^{-1}\right)$.

\section{Nisbah Pupus Akar (NPA)}

Pada Tabel 6 dapat dilihat bahwa taraf takaran pupuk kandang domba menunjukkan pengaruh yang berbeda tidak nyata terhadap NPA.

\subsection{Pembahasan}

Hasil penelitian menunjukkan bahwa perlakuan berbagai takaran pupuk kandang domba memberikan pengaruh yang nyata terhadap pertumbuhan tanaman pegagan pada umur $8 \mathrm{mst}$ dan 12 mst terhadap jumlah daun, jumlah anakan, jumlah sulur primer, bobot kering akar dan bobot kering pupus. Tetapi memberikan pengaruh yang tidak nyata terhadap bobot kering tanaman. Hasil pengamatan menunjukkan takaran $\mathrm{k}_{5}\left(25\right.$ ton ha $\left.{ }^{-1}\right)$ dan $\mathrm{k}_{4}\left(20\right.$ ton $\left.\mathrm{ha}^{-1}\right)$ memberikan pengaruh yang lebih baik.

Pemberian pupuk kandang domba akan memberikan pengaruh yang nyata terhadap tinggi tanaman, jumlah daun dan diameter batang. Peningkatan dosis pupuk kandang berbanding lurus dengan peningkatan jumlah daun. Semakin besar dosis pupuk kandang, maka tinggi tanaman dan jumlah daun semakin besar pula (Bara dan Chozin, 2009).

Pupuk kandang sangat mempengaruhi pertumbuhan daun dan jumlah anakan yang dihasilkan. Hal ini dikarenakan pupuk kandang dapat meningkatkan jumlah daun tanaman, dimana pupuk kandang domba tersebut membantu memperbaiki struktur tanah, sehingga daya serap air dan hara oleh akar tanaman meningkat, serta akibat aktivitas mikroorganisme tanah yang membantu proses penambahan $\mathrm{CO} 2$ pada permukaan tanah. Konsentrasi CO2 mempunyai pengaruh yang sangat nyata terhadap fotosintesis, dengan meningkatnya konsentrasi $\mathrm{CO} 2$ maka dapat meningkatkan laju fotosintesis (Januwati, 2002). 
Penggunaan pupuk kandang kambing secara berkelanjutan memberikan dampak positif terhadap kesuburan tanah. Tanah yang subur akan mempermudah per-kembangan akar tanaman. Akar tanaman yang dapat berkembang dengan baik akan lebih mudah menyerap air dan unsur hara yang tersedia di dalam tanah sehingga ta-naman dapat tumbuh dan berkembang secara optimal serta menghasilkan produksi yang tinggi (Dinariani, 2004).

Ketersediaan unsur hara yang terkandung dalam pupuk kandang akan menyebabkan aktivitas proses fotosintesis tanaman pegagan meningkat, karena unsur hara ini langsung dibutuhkan untuk pertumbuhan klorofil dan reaksi fotosintesis, sehingga dengan proses fotosintesis yang lancar hasil fotosintesisnya semakin tinggi yang selanjutnya ditranslokasikan ke seluruh bagian tanaman untuk pertumbuhan.

Pencampuran pupuk kandang terhadap tanah dalam takaran yang cukup juga dapat meningkatkan daya pegang air (water holding capacity). Keadaan yang demikian akan merangsang organ-organ fotosintesis menghasilkan lebih banyak karbohidrat yang dapat mendorong pertumbuhan tanaman pegagan menjadi lebih besar.

Penambahan pupuk kandang domba 5-25 ton ha ${ }^{-1}$ dapat meningkatkan bobot basah dan kering daun lebih tinggi dibandingkan dengan tanpa pupuk kandang. Hal ini dapat dimengerti mengingat peranan pupuk kandang dalam memperbaiki sifat fisik, biologis dan kimia tanah yang dapat meningkatkan pertumbuhan dan produksi tanaman dalam hal ini bobot basah daun (Soepardi, 1983).

Hal ini sesuai dengan pendapat Januwati (2002) perlakuan pupuk kandang dengan dosis 15 ton ha ${ }^{-1}$ memberikan bobot kering pegagan yang tertinggi. Peranan pupuk kandang tersebut penting terutama pada saat pegagan berumur 3 bulan dengan keadaan curah hujan yang rendah. Ketersediaan hara dan air merupakan salah satu upaya untuk meningkatkan konversi cahaya matahari ke dalam bentuk produksi tanaman dalam hal ini bobot kering daun.

\section{Kesimpulan}

Berdasarkan hasil analisis statistik maka dapat ditarik kesimpulan sebagai berikut :

1. Pemberian pupuk kandang domba berpengaruh terhadap pertumbuhan tanaman pegagan.

2. Pemberian takaran pupuk kandang domba 20 - 25 ton $\mathrm{ha}^{-1}$ berpengaruh paling baik terhadap jumlah daun, jumlah anakan, dan jumlah sulur primer pada umur 8 MST dan 12 MST, serta bobot kering akar dan bobot kering pupus tanaman pegagan pada umur 12 MST. 


\section{DAFTAR PUSTAKA}

Bara, A. dan M. A. Chozin. 2009. Pengaruh Dosis Pupuk Kandang dan Frekuensi Pemberian Pupuk Urea terhadap Pertumbuhan dan Produksi Jagung (Zea mays L.) di Lahan Kering. Dalam Kumpulan Makalah Seminar Hasil Peelitian Departemen Agronomi dan Hortikultura Fakultas Pertanian Institut Pertanian Bogor. Bogor.

Deptan. 2007. Prospek dan Arah Pengembangan Agribisnis Tanaman Obat. http//www.litbang.go.id (12 februari 2013).

Dinariani,. 2014. Jurnal Produksi Tanaman, Volume 2, Nomor 2, Maret 2014, hlm. 128-136

Ghulamahdi, M., S.A. Aziz, N. Bermawie, dan O. Trisilawati. 2008. Laporan Hasi Penelitian Studi Penyiapan Standar Operasional Prosedur Budidaya Untuk Produksi Bioaktif Mendukung Standarisasi Mutu Pegagan. Institut Pertanian Bogor. 70 hal.
Januwati, M dkk. 2002. Pengaruh Dosis Pupuk Kandang dan Tingkat Populasi Terhadap Petumbuhan dan Produksi Pegagan (Cetella asiatica (L) Urban) di Bawah Tegakan Kelapa (Cocos nucifera L). Jurnal Bahan Alam Indonesia. Vol 1. No.2. 9 Hal.

Januwati, M. dan M. Yusron. 2005. Budidaya tanaman pegagan. http//balittro.litbang.deptan.go.id. [22 November 2008].

Soepardi, G. 1983. Sifat dan Ciri Tanah. IPB. Bogor. 591 hal.

Tipatmasari, M. 2010. Pemanfaatan Naungan dan Pupuk Kotoran Sapi Terhadap Pertumbuhan dan Kandungan Triterpenoid Pegagan (Centella asiatica L Urban). Agrovigor Vol. 3 No.2. 8 Hal.

Winarto, W.P dan M. Surbakti. 2003. Khasiat dan Manfaat Pegagan: Tanaman Penambah Daya Ingat. AgroMedia. Jakarta. 64 hal. 